\title{
Not invented here: Transferability of congestion charges effects
}

Maria Börjesson, Karin Brundell-Freij and Jonas Eliasson

The self-archived postprint version of this journal article is available at Linköping University Institutional Repository (DiVA):

http://urn.kb.se/resolve?urn=urn:nbn:se:liu:diva-181296

N.B.: When citing this work, cite the original publication.

Börjesson, M., Brundell-Freij, K., Eliasson, J., (2014), Not invented here: Transferability of congestion charges effects, Transport Policy, 36, 263-271. https://doi.org/10.1016/j.tranpol.2014.09.008

Original publication available at:

https://doi.org/10.1016/j.tranpol.2014.09.008

Copyright: Elsevier

http://www.elsevier.com/

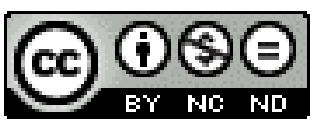




\title{
Not Invented Here: Transferability of congestion charges effects
}

\author{
Maria Börjesson, Karin Brundell-Freij, Jonas Eliasson \\ Published in: \\ Transport Policy, 2014, vol. 36, p. 263-271.
}

\begin{abstract}
The purpose of this paper is to explore to what extent the effects of congestion charges rely on specific features of a city and its transport system. We use Stockholm, and its current congestion charging scheme, as a case study by making various modifications in the transport system influencing the availability and attractiveness of public transport, bypasses and bottleneck capacities. We use a transport model to forecast the effects of the Stockholm charges given each transport system modification. Our main conclusion is that although the social benefit of a given charging system is considerably and non-linearly dependent on initial congestion levels, traffic effects and adaptations costs are surprisingly stable across transport system modifications. Specifically, the level of public transport provision has only small effects on baseline congestion, and therefore on the total benefit of the charges. Contrary to expectation, the charges' effect on traffic volumes remains virtually unchanged regardless of the changes in public transport supply. All results are compared to and consistent with the one-market standard model. We interpret our results with respect to common arguments against the transferability of experiences from cities having introduced congestion charges.
\end{abstract}

Keywords: Congestion pricing, transport modeling, marginal cost pricing, policy transfer 


\section{INTRODUCTION}

Although congestion charging has been considered to be an efficient remedy to congestion problems for decades (Vickrey, 1973), implementation has been held back by lack of public and political support (Jones, 2003; Schade and Schlag, 2003). Several authors have noted that a main reason for this skepticism is the belief that they will not "work"(Bartley, 1995; Börjesson et al., 2012; Eliasson and Jonsson, 2011; Eliasson, 2008; Jones, 2003; Schlag and Schade, 2000). In the words of Jones (2003): "The public not only dislikes charges, it thinks it will not be effective".

Indeed, the authors of this paper can verify this. Having presented the experiences from Stockholm and other cities with congestion pricing to audiences from all over the world, we can testify that a common response is "congestion pricing may be effective in Stockholm/London/Singapore/... - but it doesn't suit our city, because [we don't have a ring road]/[our public transport system is not good enough]/[traffic would just change routes]/[we simply need more road capacity]/..." or other similar arguments. Attard and Enoch (2011) report similar reactions for Valetta, Malta: “...Valletta cannot be compared to London or Stockholm simply because it is too small".

The Stockholm congestion charging system, consisting of a time-varying toll at the bottlenecks on the arterials to the inner city, turned out to reduce congestion efficiently. Traffic across the cordon was reduced by about $21 \%$, and the effects have remained stable since it was first introduced in 2006 (Börjesson et al., 2012). As a result, travel times have decreased dramatically, especially on the arterials but also in the inner city (Eliasson, 2008). London experienced similar effects (Leape, 2006; Santos and Shaffer, 2004). If the experiences from London and Stockholm are found to be transferrable between transport systems, this may help to increase the general support in other cities and to meet arguments such as those exemplified above. The main objective of this paper is to explore the transferability of the traffic effects of the Stockholm congestion charges.

Understanding the transferability of the effects of congestion pricing is essential, because acceptance tend to increase if the charges are expected to have substantial traffic effects (Eliasson, 2008; Börjesson et al. 2012; Bartley, 1995), while the public generally does not trust charges to be an effective tool for combating congestion. Such distrust is therefore at least part of the explanation to why congestion charging has only rarely been implemented.

We examine whether the effects experienced in Stockholm hinge upon particular features of the city, investigating to what extent the effectiveness and efficiency of the Stockholm charges rely on specific features of the Stockholm transport system. We focus on the most common arguments used to question the transferability of the Stockholm experiences, such as: we do not have such an efficient and extensive public transport system as Stockholm or if we had better public transport we would not need congestion pricing; we do not have a bypass like Stockholm has or if we had more bypasses we would not need congestion pricing; if we had more road capacity, we would not need congestion pricing. The present study is designed to specifically explore these arguments and to what extent they can be rejected or supported.

To this end, we use a transport model to forecast the effects of the Stockholm charges given transport system scenarios. The scenarios are constructed by making various modifications of the road and public transport systems, such as those indicated above: availability and attractiveness of public transport, bypasses and bottleneck capacities. 
The transport model we use was able to predict the traffic reduction when the charges were first introduced (Eliasson et al., 2013), which suggests that the model will also be able to predict what would happen assuming these various modifications on the transport system.

We find that traffic reductions and adaptation strategies to a large extent are transferable between different transport systems, but that travel time reductions, and therefore welfare benefits, depend considerably and non-linearly on initial congestion levels. However, even if these results do suggest a high transferability of congestion charging, design variables such as charge levels, time differentiation, checkpoint locations, exemptions etc. must be based on local characteristics (Eliasson, 2010). Dolowitz and Marsh (2000) point out that inappropriate policy transfer (with insufficient attention being paid to differences between policy contexts) is a strong risk factor in policy transfer.

Policy transfer and policy diffusion have become an increasingly more important part of policy formation both in general (Dolowitz and Marsh, 2000) and for transport policy in particular (Marsden and Stead, 2011; Timms, 2011). For the specific case of congestion charging policies, there is evidence of an increasing interest to learn from the lessons of others, and investigate the transferability of policies (Attard and Enoch, 2011; Marsden and Stead, 2011; Richardson and Bae, 2008).

Assuming that policy transfer and diffusion are real and plays a role, the successful implementation of congestion charging in London and Stockholm would be expected to wither the distrust in the effectiveness of this policy measure. And congestion charging would have been expected to be implemented in many other cities with congestion problems. And indeed, the implementation of congestion charging has increased in later years, and the London and Stockholm experiences seem to have played a role for other cities considering congestion charges (Marsden et al., 2010, Attard and Enoch, 2011). But a number of cities have still declined concrete congestion charging proposals at different stages of decision making, for example Edinburgh, Manchester, Helsinki and Copenhagen. In all those cases lack of public acceptance has been a key factor for why the proposals failed. Hence, it seems that many people in cities around Europe still are not convinced that congestion charging would be an efficient way to combat congestion.

The paper is outlined as follows. In section 2 we describe the Stockholm congestion charging system and the main effects on the transport system. In section 3 we describe how and motivate why the present transport system are modified in the scenarios. Section 4 uses the static one-link model to develop hypothesis on how the most relevant baseline conditions and effects of the charges will differ between scenarios. Section 5 describes the transport model and how output indicators are computed from the model output. Section 6 reports the results and section 7 concludes.

\section{THE STOCKHOLM CONGESTION CHARGES}

The Stockholm congestion charging system consists of a toll cordon, with charging points located at or near the main bottlenecks on the arterials leading into the inner city. The City of Stockholm has around 0.8 million inhabitants, and is the central part of the Stockholm county, with a total of 2 million inhabitants. Out of the almost 300000 inhabitants within the toll cordon, approximately 60,000 commute to workplaces outside of the zone. The area within the cordon has close to 23,000 workplaces, employing approximately 318,000 persons, of which more than two-thirds are 
commuting from outside the zone. Before the introduction of the charges the volumes across the cordon was a little less than 500000 vehicles per day.

Stockholm has an extensive public transport system, including the Metro, commuting trains, trams and buses running to and from the inner city. The share of public transport trips to and from the inner city reaches $75 \%$ during peak hours, and the Metro takes $57 \%$ of these. Central Stockholm is built on several islands connected by bridges, which means that travelling distances are relatively long and road congestion spreading out from the bottlenecks around the inner city is high.

The cost ${ }^{1}$ of passing the cordon in any direction on weekdays is $€ 2$ during peak hours (7:30-8:30, 16:00-17:30), $€ 1.5$ during the shoulders of the peaks ( 30 minutes before and after peak period) and $€ 1$ during the rest of the period 6.30-18.302. The charge is levied in both directions. The Essinge bypass (E4/E20) is the only free-of-charge passage between the north and south part of the county. It is also the most important bottleneck in the system that remains uncharged. It was heavily congested before the charges were introduced and the charges did not affect the level of congestion to any great extent (Börjesson et al., 2012). However, politicians have regarded it as essential for public acceptance that there is a non-charged connection between the southern and northern parts of the county.

When the charges were introduced in 2006, traffic across the cordon decreased over $20 \%$ (average over the charged period), meaning that traffic was down to levels not seen since the 1970's, reducing queuing times by $30-50 \%$. On some links and routes, the effects were even larger. Despite this, circumferential traffic (including the Essinge bypass) did not increase. Around half of the diverted car drivers changed to public transport. Still, crowding did not increase appreciably since this only increased public transport volumes by a few per cent (in rush hours, PT volumes are almost three times larger than car volumes across the cordon).

The traffic effects were relatively close to the forecast effects from the national transport model Sampers (see section 5), in the sense that effects were predicted well enough to allow planners to draw correct conclusions regarding the design and preparations for the scheme (Eliasson et al., 2013). Still, the predicted response to the charges was so large that several experts considered the forecasts unrealistic. As it turned out, however, the model gave much more accurate predictions than experts' judgments, in addition to providing more detail and consistency. The skepticism towards the predictions was understandable: the introduction of the congestion charges affected the whole Stockholm road transport system in a completely unprecedented way.

\footnotetext{
${ }^{1}$ We have converted SEK to Euro using a conversion rate of $10 \mathrm{SEK} / €$.

${ }^{2}$ Recent model simulations suggest that increasing the charge in rush hours would improve social surplus. In other words, the current charge seems to be below the marginal external cost, considering the macroscopic relation between traffic flow across the cordon and congestion in and around the inner city. The optimal rush hour charge (yielding maximal social surplus) seems to be in the range 3$4 €$. These results are uncertain because of the difficulties to integrate demand models with the dynamic traffic assignment models needed to capture congestion accurately, but they were part of the motivation of politicians to decide to increase rush-hour charges in 2016.
} 


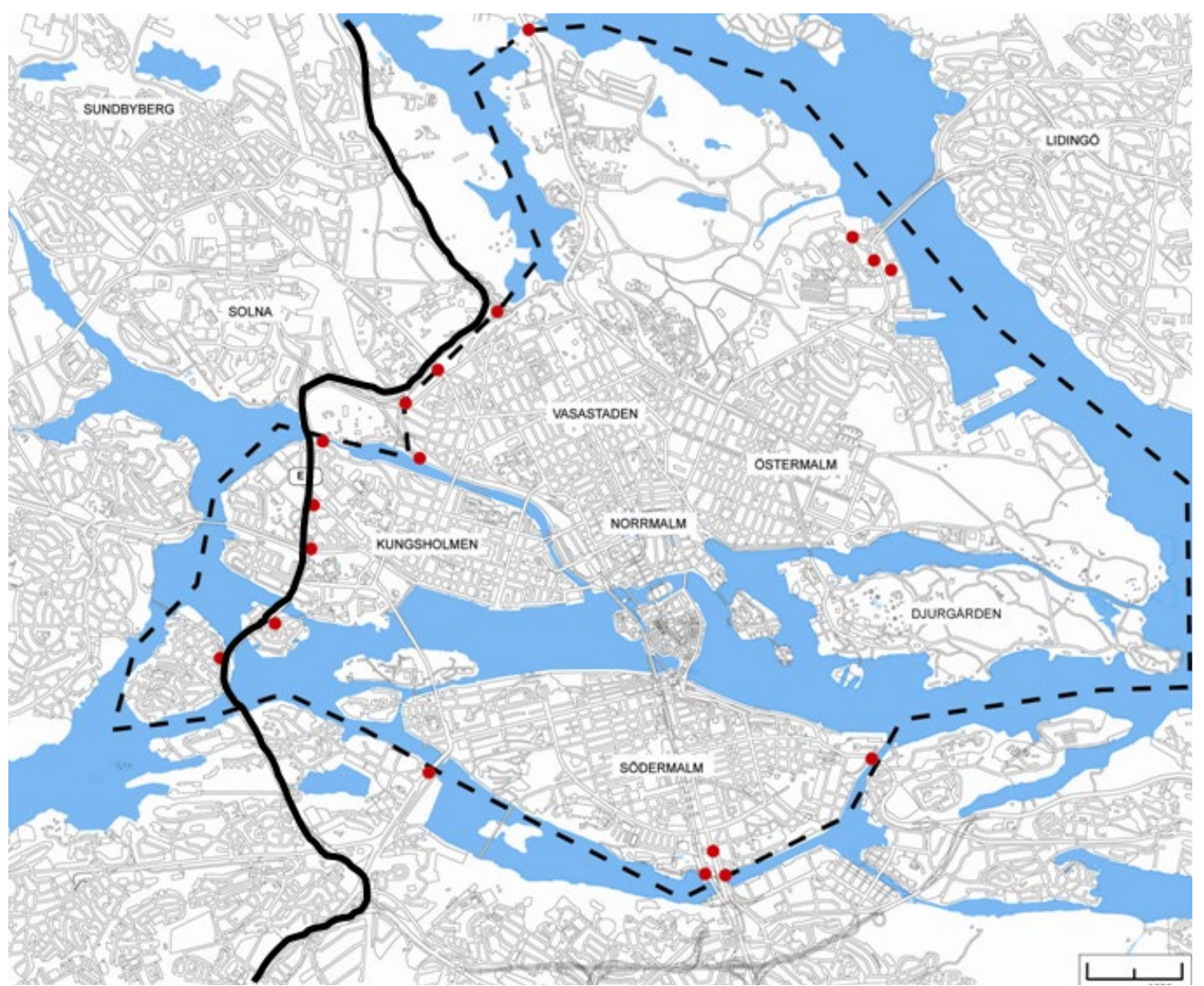

Figure 1 The charged area. The dashed line is the charging cordon, the dots are charging points and the solid line is the non-charged Essinge bypass.

An overview of the effects of the Stockholm congestion charges can be found in (Börjesson et al., 2012; Eliasson, 2008; Eliasson et al., 2009), where the first also discusses the main lessons from the trial in terms of design, effects, acceptability and political process.

\section{SCENARIO DEVELOPEMENT}

The starting point in this study is the effects of the current congestion charging scheme in Stockholm, assuming the current transport system. While assuming the same pricing scheme, we then make changes in the transport system, increasing or reducing the availability and the quality of the public transport system, bypasses in the road network and capacity of the charged links (which are the arterials leading to the inner city). This results in six different transport system scenarios, and for each scenario we assess the effect of the congestion charges by comparing the model-computed traffic situation in a baseline situation (without charging) and a charged situation.

The scenarios have been formed by modifications of the road and public transport systems. They focus on features that distinguish Stockholm from many other cities and therefore would speak against transferability: the high share of public transport, the severe bottlenecks leading to the inner city, a bypass that can be used to avoid charging for traffic passing the charged area and the lack of capacity on this single bypass. The modifications are also chosen to explore the relevance of five common arguments against transferability of the Stockholm effects:

1. If we had better public transport we would not need congestion pricing 
2. Our public transport is less extensive than in Stockholm so charging would not have any effect

3. If we had more bypasses congestion pricing would not be need

4. We do not have a bypass where priced off drivers can divert so charging would not have any effect

5. If we had more road capacity on the arterials we would not need congestion pricing

The six scenario specifications, names and related argument are summarized in Table 1. The common theme for all arguments is that it is the magnitude of the elasticities that is questioned: the price elasticity for car trip frequency, route and destination choices as well as cross-elasticities between different modes. Another doubt seems to be whether a moderate reduction of car traffic in the bottlenecks ( $\sim 20 \%$ or less) would have any significant impact on travel times. This will be in focus in the interpretation of the results.

Table 1: Six scenarios.

\begin{tabular}{|l|l|l|}
\hline Name of scenario & Argument & $\begin{array}{l}\text { Change compared to real } \\
\text { Stockholm }\end{array}$ \\
\hline Reference & & Representing Stockholm 2006 \\
\hline Public transport + & $\begin{array}{l}\text { 1. "If public transport was better, congestion } \\
\text { charges would not be needed" }\end{array}$ & $\begin{array}{l}\text { PT supply increase (+100\%) } \\
\text { PT travel times reduced (approx. - } \\
20 \%)\end{array}$ \\
\hline Public transport- & $\begin{array}{l}\text { 2. "Congestion charges won't work in our city, } \\
\text { because our public transport isn't good enough" }\end{array}$ & $\begin{array}{l}\text { PT supply reduced (-50\%) } \\
\text { PT travel times up (approx. }+30 \%)\end{array}$ \\
\hline Bypass + & $\begin{array}{l}\text { 3. "If we had more bypasses, congestion charges } \\
\text { would not be needed" }\end{array}$ & $\begin{array}{l}\text { A new, uncharged bypass with high } \\
\text { standard is added to the east of } \\
\text { Stockholm }\end{array}$ \\
\hline Bypass - & $\begin{array}{l}\text { 4. "Congestion charges won't work in our city, } \\
\text { because we don't have a bypass" }\end{array}$ & Essinge bypass closed for traffic \\
\hline Capacity + & $\begin{array}{l}\text { 5. "If we had more road capacity, congestion } \\
\text { charges would not be needed" }\end{array}$ & $\begin{array}{l}\text { Capacity on all access roads to } \\
\text { inner city doubled }\end{array}$ \\
\hline
\end{tabular}

In all six scenarios, the currently implemented charging system applies, with identical charges and checkpoint locations. The charge is kept constant over scenarios, although baseline congestion, and therefore the optimal charge, will vary. Given the difficulties in determining and implementing an optimal real-world charging system, keeping the charging system the same across scenarios seems most realistic and facilitates conclusions ${ }^{3}$.

\section{WHAT DIFFERENCES BETWEEN SCENARIOS CAN BE EXPECTED?}

To develop some hypotheses on how the different scenarios discussed in section 3 will influence the traffic system and responses to the pricing scheme, we first analyze the scenarios in the standard static single-market model. This model cannot be used to determine effects of a real congestion charging system because it is based on strong and unrealistic assumptions, as pointed out by for example Lindsey and Verhoef (2000). It ignores heterogeneity in the value of time, dynamic effects including re-scheduling, and travel time reductions arising for traffic outside the charged market. For all these reasons the standard single-market model can only give a rough indication of the expected effects

\footnotetext{
${ }^{3}$ The congestion charge levied in Gothenburg (also a cordon based system similar to the one in Stockholm) is for instance almost the same as in Stockholm although Gothenburg has considerably less congestion. Moreover, neither the Stockholm nor the Gothenburg system can be optimal because they are cordon based with a unit price at all links and directions (mainly for the reason of public acceptance) although congestion varies considerably in these dimensions.
} 
in a real congestion charging system. The single-market model is still useful as a benchmark, in order to understand the mechanisms of how the effects and efficiency of charging can be expected to vary between different traffic systems.

To set the stage, Figure 1 shows the analysis of an optimal congestion charge in this model. This analysis has been thoroughly discussed in the literature (Hau, 1992; Walters, 1961). $\mathrm{MC}$ is the marginal cost, $\mathrm{AC}$ is the average cost, $\mathrm{D}$ is the inverse demand curve, $c$ is the generalized travel cost (travel time and charge) and $f$ is the traffic volume. $c_{0}$ is the average generalized cost meeting the drivers and $f_{0}$ the resulting traffic flow in the baseline situation without a charge. In the situation with an optimal charge $\left(\tau^{*}\right)$, the resulting travel time is $c_{1}$ and the traffic flow is $f_{1}$. The generalized travel cost is $\mathrm{c}^{*}$. The optimal charge $\left(\tau^{*}\right)$ is set such that demand D meets the marginal cost MC. The darkest triangle [I-II-III] equals the net social benefit generated by the system ${ }^{4}$. It can be decomposed as the difference between: i) the value of reduced travel time for remaining road users $\left[\mathrm{c}^{*}-\mathrm{V}-\mathrm{IV}-\mathrm{c}^{0}\right]$ and ii) the welfare loss of drivers priced off the road, i.e. the adaptation cost [IV-I-III].

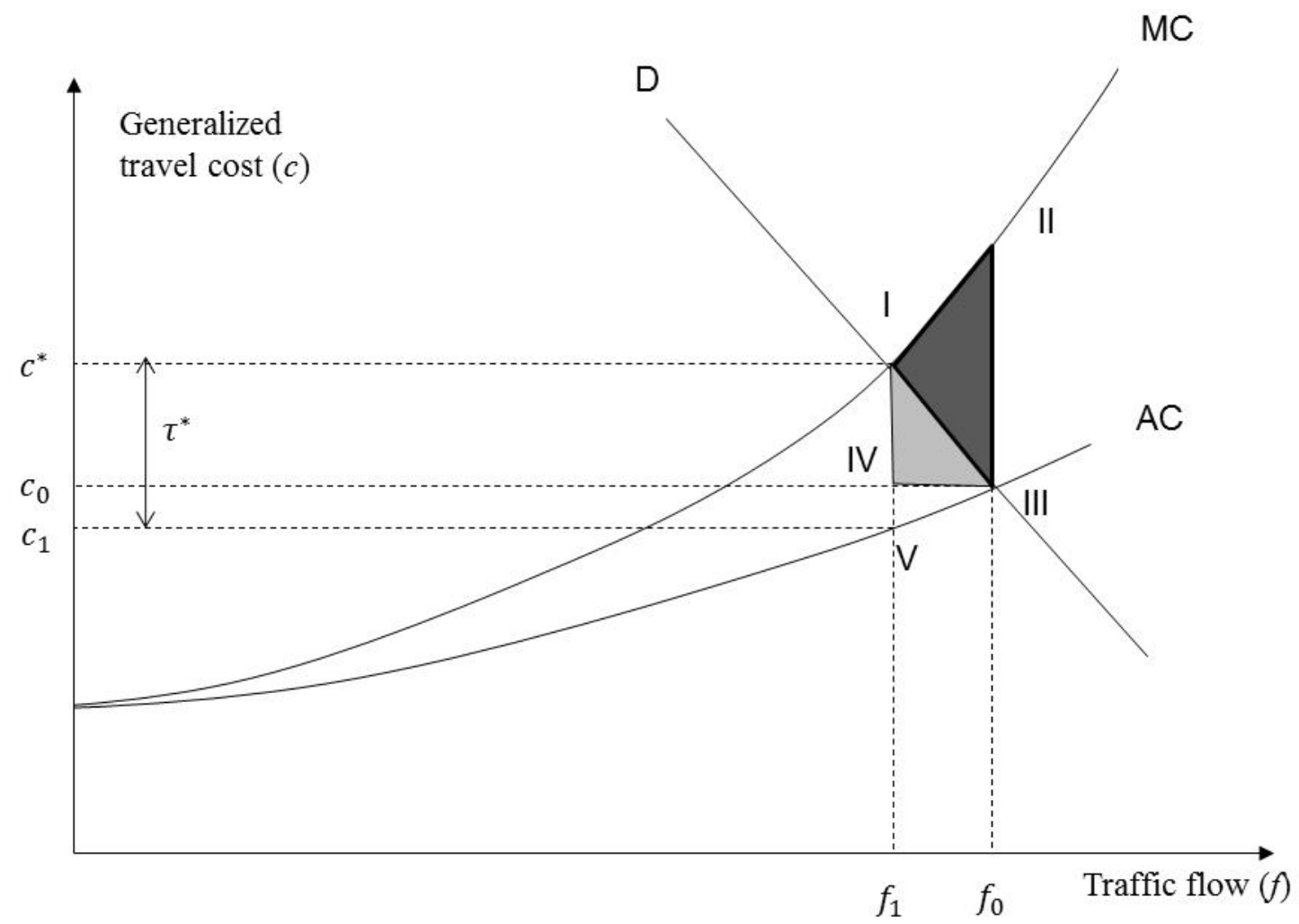

In the analyses in this paper we will not assume the optimal charge as in Figure 2, since we do not assume an optimal charge in the analysis and instead keep it constant across scenarios as discussed in Section 3. In the following, we will study comparative statics given the same size of the congestion charge when the demand and supply curves vary.

In the standard single-market model better alternatives to the charged links affect the demand in two ways: the demand decreases (the demand curve shifts inward) and the cost elasticity increases (the slope changes). In the scenarios Bypass+ and Public

${ }^{4}$ In this paper we ignore the running cost of the system. 
Transport+, alternatives are improved, while in the scenarios Bypass- and Public Transport- alternatives become worse.

To simplify first, Figure 3a describes a situation where the demand curve D in the initial situation shifts inward to $\mathrm{D}^{\prime}$, but the slope of the demand curve, $-k$, remains constant. As a result of this shift, average and marginal cost of driving changes, implying that the optimal charge and the welfare effect of this charge also changes. The figure assumes that the non-optimal charge $\tau$ remains constant. In the situation $\mathrm{D}$, the congestion charge is smaller than the optimal charge. In the situation D' the same congestion charge $\tau$ is larger than what is optimal because the optimal charge decreases when the demand curve shifts inwards. The total benefit of the charge corresponds to the dark area in the D situation. In the D' situation the total benefit corresponds to the large dark area minus the smaller medium-dark triangle.

Assuming a (locally) linear AC curve with slope $m$ and constant slope $-k$ of $\mathrm{D}$, we have that the demand reduction of the charge $\tau$ is (see appendix):

$$
f_{0}-f_{1}=\frac{\tau}{k+m} .
$$

The demand reduction of the charge $\tau$ thus increases when the demand curve changes from $\mathrm{D}$ to $\mathrm{D}^{\prime}$ since $m$ is smaller to the left. The travel time (the part of the generalized cost that is not the charge) reduction, however, decreases with smaller $m$ :

$$
c_{0}-c_{1}=\frac{\tau m}{m+k} .
$$

The adaptation cost (the light grey triangle, partly covered) is (see appendix):

$$
\text { adaptation } \cos t=\frac{k \tau^{2}}{2(k+m)^{2}} \text {. }
$$

This increases when the demand curve shifts from $D$ to $D^{\prime}$, because $i$ ) the drivers priced off the road incur a higher welfare loss since the total price of a car trip increases more than in the D situation and ii) more drivers are priced off the road. The adaptation cost thus increases as more alternatives become available. This may seem counterintuitive, but it is because the charge remains the same in the two scenarios. 


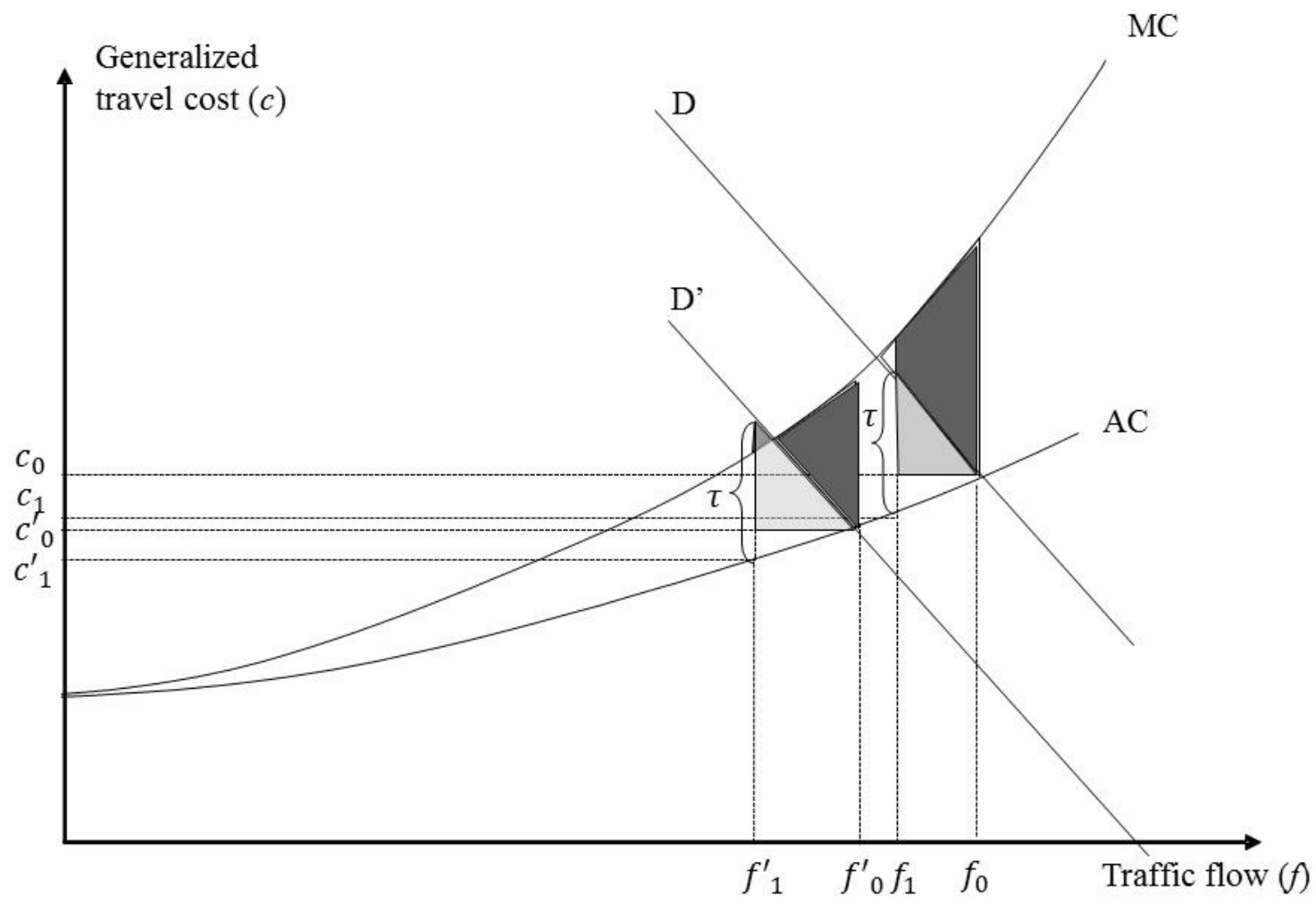

a) Parallel shift of the demand curve

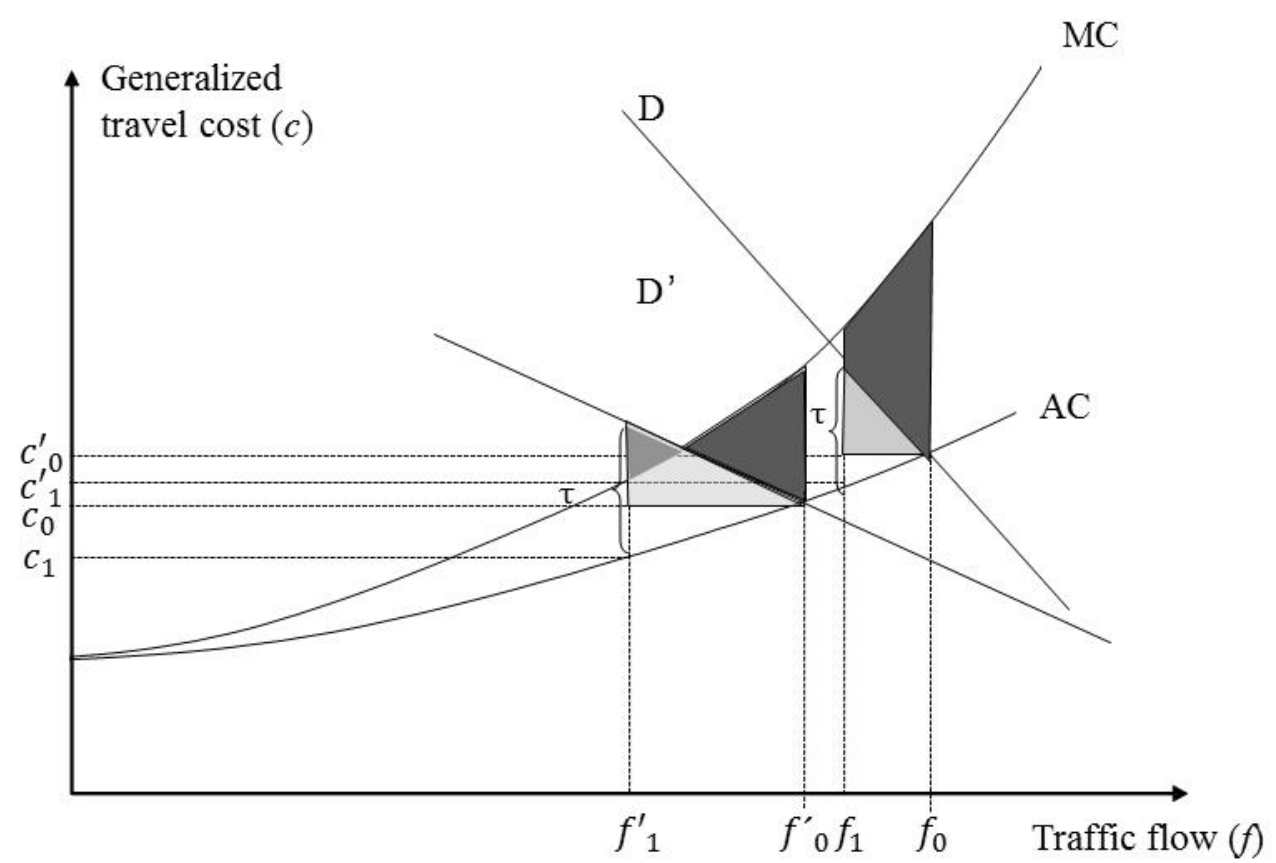

b) The demand curve shifts and changes its slope.

Figure 3: The effect of a fixed congestion charge $\tau$ (not optimal) applied under different demand conditions: demand curve $D$ and initial demand fo (high demand), and demand curve $D^{\prime}$ and initial demand fo' (low demand). 
Figure 3(b) shows the case where the demand curve shifts as in 3 (a) and become more elastic, i.e. $k$ decreases. When the demand becomes more elastic the charge increases the demand reduction $\left(f_{0}-f_{1}\right)$ even more than in 3(a) (see eqn. (1)). Reducing $k$ also increases the travel time reduction $c_{1}-c_{0}$ (see eqn. (2)). If the demand curve shifts to the left and decreases its slope, the effect on the travel time reduction $c_{1}-c_{0}$ from a fixed charge can thus be either positive or negative.

Increased demand elasticity will also affect the adaptation cost. The direction of this impact depends on $k$ and $m$, because on the one hand increased elasticity increases the number of drivers priced off the road, but on the other hand it reduces the average adaptation cost for each driver (since the total generalized cost of the remaining car trips increases less). If $k<m$ (high congestion) then increased demand elasticity will decrease the adaptation cost (see eqn. (3)). If $k>m$ (low congestion) then increased demand elasticity will increase the adaptation cost. When the demand curve shifts and becomes more elastic as in Figure $3 \mathrm{~b}$, the adaptation cost will thus increase when congestion is low (small $m$ ). Again this may seem counterintuitive, but it is because the charge remains unchanged although the optimal charge is reduced. In a situation with high congestion the adaptation cost can decrease or increase when demand shifts from D to D' as in Figure 3(b).

The scenario Capacity+ is illustrated in Figure 4; the same demand D will cause less congestion when capacity is increased. The impact on demand, travel time reduction and adaptation cost are straightforward from eqn (1)-(3).

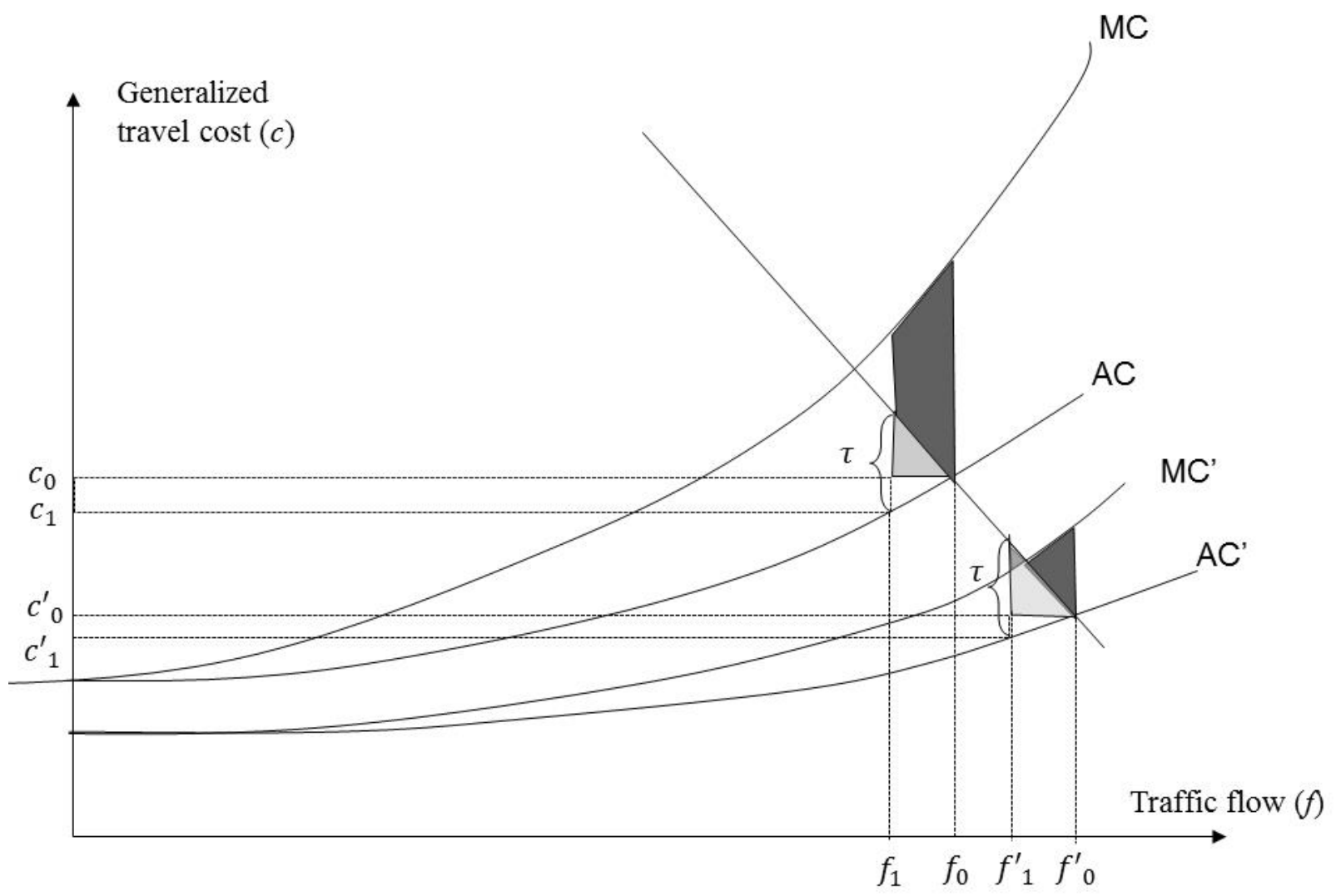


Figure 4 Two different baseline conditions for a given supply: f0/AC/MC (little capacity), and f0'/AC' /MC' (more capacity).

With respect to capacity and availability of alternative travel options we summarize the expectations generated from the standard model in Table 2. It summarizes on how the baseline conditions and effects of charging will differ between scenarios. These indicators are useful for analyzing the most common arguments against transferability, essentially questioning the magnitude of effects on car trip frequency, route and destination choices. 
Table 2: Summary of expectations generated by the standard model (Figures 3 and 4). Effects are in the scenarios Bypass- and Public Transport- are exactly the opposite those indicated for Bypass+ and Public Transport+.

\begin{tabular}{|c|c|c|c|c|c|c|c|}
\hline & & \multicolumn{2}{|c|}{ Baseline conditions } & \multicolumn{3}{|c|}{ Traffic effects of charging } & \multirow{2}{*}{$\begin{array}{r}\text { Efficiency } \\
\text { Total ne } \\
\text { benefit }\end{array}$} \\
\hline & & $\begin{array}{c}\text { Baseline } \\
\text { volume } \\
f^{0}\end{array}$ & $\begin{array}{l}\text { Travel } \\
\text { time } \\
\text { delay } \\
c^{0}\end{array}$ & $\begin{array}{l}\text { Volume } \\
\text { reduction } \\
f^{*}-f^{0}\end{array}$ & $\begin{array}{l}\text { Travel time } \\
\text { reduction } \\
c^{*}-c^{0}\end{array}$ & $\begin{array}{c}\text { Adaptation } \\
\text { cost }\end{array}$ & \\
\hline \multirow[t]{2}{*}{$\begin{array}{l}\text { Improved alternatives } \\
\text { (Bypass }+ \text { and Public } \\
\text { transport }+ \text { scenarios) }\end{array}$} & $\begin{array}{l}\text { Elasticity } \\
\text { remains } \\
\text { constant } \\
\text { Figure 3(a) }\end{array}$ & - & - & + & - & + & - \\
\hline & $\begin{array}{l}\text { Elasticity } \\
\text { increases } \\
\text { Figure 3(b) }\end{array}$ & - & - & + & + or - & + or - & + or - \\
\hline $\begin{array}{l}\text { Higher capacity on } \\
\text { charged links } \\
\text { (Capacity }+ \text { scenario) }\end{array}$ & Figure 4 & + & - & + & - & + & - \\
\hline
\end{tabular}

\section{MODELING RESULTS}

\subsection{The transport model}

The national transport model Sampers (Beser Hugosson and Algers, 2002) was used when designing the charging system to predict the effects. We use the same model in the present analysis. The travel demand model in Sampers consists of nested logit models for six trip purposes (Work, School, Business, Recreation, Social and Others), modeling choices of trip frequency, destination and mode (car as driver, car as passenger, public transport, walk and cycle). The demand models are limited to private trips and business travel, while demand for freight and delivery/professional services is fixed and added before network assignment. There are three analyzed time periods, over which demand is distributed using fixed time period factors per trip purpose applied uniformly to all origin-destination pairs. Road and transit link flows are calculated using the software package EMME/3 (INRO, 2010). Road flows are calculated using multiclass static assignment, where trips from the demand models are segmented into five value-of-time classes. The transit assignment is based on the optimal strategies.

Static assignment models generally underestimate travel time reductions caused by reduced traffic volumes when there is severe bottleneck congestion, since such models do not account for spillback congestion upstream the bottlenecks on the arterials. However, previous analyses have shown that in the Stockholm case, this is mainly a problem for non-charged links since it is mainly there that spillback congestion is reduced (Eliasson et al., 2013). The static volume-delay functions actually worked sufficiently well on the charged links; the travel time reductions for traffic through the bottlenecks were only underpredicted by $4 \%$ on average. This is reassuring and explains why the model predicts the volume reduction over the cordon reasonably well. But since the model disregards spillback congestion, travel times were actually predicted to increase on links outside the cordon, whereas they in reality decreased considerably. 
The aggregate travel time reduction on links inside the cordon was underpredicted by on average $34 \%$.

The travel time reductions presented in the result section can therefore be interpreted as the travel time reductions experienced by the charged traffic, but not as the travel time reductions in the entire network.

Sampers can be described as state-of-practice for large-scale transport models. Its structure - logit demand models linked to a network assignment model - resembles most operational, large-scale transport models. It does not include more advanced features such as departure time choice or activity-based travel demand, but has been carefully estimated using state-of-the-art methods, and calibrated and validated against travel survey and traffic volume data.

\section{RESULTS}

The theoretical analyses in the preceding section show what results we should expect when the same congestion charging system is introduced in the six different scenarios. Table 3 and Table 4 summarizes modeling results. The first three columns of Table 3 show congestion indices for each scenario in the baseline situation (without charging). The first congestion index 5 measures the average congestion level on the arterials leading into the inner city, and the second index measures average congestion on inner city streets. The third index is a weighted average of the two first (according to traffic volumes). The next two columns of Table 3 show traffic volumes across the cordon in the baseline situation, and the next two how much this is reduced by the charges. The final column shows how much of the disappearing traffic is diverted to public transit (most of the remaining diverted traffic change to other destinations, although some change to other routes and some trips disappear).

Table 4 shows monetary benefits of the charges in the six scenarios: travel time savings for remaining traffic 6 , adaptation costs for diverted traffic, and total benefits (the sum of the two and the increased driving costs due to rerouting). Since the transport model vastly underpredicted the travel time savings for the uncharged traffic, while predicting the travel time savings for the charged traffic reasonably well, the reported travel time savings should be interpreted as the travel time savings for the charged traffic. For the same reason the congestion index for the arterials can be expected to reflect the congestion on the arterials reasonably well, but underpredict changes in congestion in the inner city.

\footnotetext{
5 The congestion index is defined as $\frac{c_{0}}{c_{f}}-1$, where $c_{0}$ is the morning peak travel time on the link and $c_{f}$ is the free flow travel time. Both $c_{0}$ and $c_{f}$ is output from the assignment model. The index is averaged over the selected links.

${ }^{6}$ The one-market model discussed in Section 4 refers to the travel time savings perceived by each individual remaining car driver whereas Table 4 refers to the total travel time savings for all remaining drivers. However, since the remaining drivers are rather stable between the scenarios, the relative size of the total travel time reductions in Table 4 also reflects the relative size of the travel time reductions that would be perceived by each individual remaining car driver.
} 
Table 3: Six scenarios: baseline congestion and cordon volumes, change in traffic across cordon by the charges and share of diverted traffic that switches to public transport.

\begin{tabular}{|l|c|r|r|r|r|r|}
\hline & $\begin{array}{c}\text { Baseline } \\
\text { congestion } \\
\text { index 1: } \\
\text { Arterials } \\
\text { towards } \\
\text { city, } \\
\text { morning } \\
\text { peak }\end{array}$ & $\begin{array}{c}\text { Baseline } \\
\text { congestion } \\
\text { index 2: } \\
\text { Inner city } \\
\text { streets, } \\
\text { morning } \\
\text { peak }\end{array}$ & $\begin{array}{c}\text { Congestion } \\
\text { index } \\
\text { (weighted } \\
\text { average of } \\
\text { index 1 and } \\
\text { 2) }\end{array}$ & $\begin{array}{c}\text { Baseline } \\
\text { cordon } \\
\text { volume, } \\
\text { thousand } \\
\text { vehicles per } \\
\text { day during } \\
\text { charged } \\
\text { time period }\end{array}$ & $\begin{array}{c}\text { Relative } \\
\text { traffic } \\
\text { reduction } \\
\text { (charged } \\
\text { time period) }\end{array}$ & $\begin{array}{c}\text { Share of } \\
\text { diverted car } \\
\text { trips that } \\
\text { change to } \\
\text { public } \\
\text { transport }\end{array}$ \\
\hline Reference & 0.97 & 0.73 & 0.88 & 378058 & $-16 \%$ & $29 \%$ \\
\hline $\begin{array}{l}\text { Public } \\
\text { transport }+\end{array}$ & 0.95 & 0.71 & 0.86 & 374771 & $-16 \%$ & $28 \%$ \\
\hline $\begin{array}{l}\text { Public } \\
\text { transport - }\end{array}$ & 1.01 & 0.76 & 0.92 & 382480 & $-15 \%$ & $29 \%$ \\
\hline Bypass + & 0.75 & 0.48 & 0.65 & 355789 & $-23 \%$ & $28 \%$ \\
\hline Bypass - & 1.03 & 0.92 & 0.99 & 448314 & $-16 \%$ & $36 \%$ \\
\hline Capacity+ & 0.78 & 0.75 & 0.77 & 386365 & $-16 \%$ & $29 \%$ \\
\hline
\end{tabular}

Table 4: Benefits generated by the charging system in different scenarios (million $€ /$ year).

\begin{tabular}{|l|r|r|r|}
\hline & $\begin{array}{c}\text { Travel time reduction } \\
{[M € / y]}\end{array}$ & $\begin{array}{c}\text { Adaptation cost } \\
\text { [M€/y] }\end{array}$ & \multicolumn{2}{c|}{$\begin{array}{c}\text { Total benefits } \\
\text { [M€/y] }\end{array}$} \\
\hline Reference & 14.0 & -5.4 & 8.6 \\
\hline $\begin{array}{l}\text { Public } \\
\text { transport }+\end{array}$ & 13.6 & -5.4 & 9.3 \\
\hline $\begin{array}{l}\text { Public } \\
\text { transport }-\end{array}$ & 14.7 & -5.4 & 3.0 \\
\hline Bypass + & 9.2 & -6.2 & 33.4 \\
\hline Bypass - & 38.7 & -5.3 & 7.4 \\
\hline Capacity + & 12.9 & -5.5 & \\
\hline
\end{tabular}

\section{The impact of public transport service levels}

In the Better Public Transport (PT+) scenario, traffic volumes and hence congestion in the baseline are reduced compared to the reference scenario. Conversely, traffic volumes and congestion increase in the Worse Public Transport (PT-). However, these changes are rather small considering the substantial changes in public transport supply in the scenarios. Model results (not reported in the tables) show that PT ridership changes considerably between the scenarios, but apparently, this is not because the car traffic volumes change a lot.

Contrary to the common argument, the charges' effect on traffic volumes remain virtually unchanged (in relative terms) regardless of the changes in PT supply. The reductions do change in the expected direction - slightly larger in the PT+ scenario, slightly smaller in the PT- scenario - but the differences between scenarios are negligible.

Because of higher congestion in the baseline, the travel time reduction is slightly higher in the PT+ scenario, and vice versa in the PT- scenario, but the difference between scenarios are small. The adaptation costs remain unchanged. Total benefits thus change in the expected way as congestion levels change: higher benefits in the PT- scenario when congestion is higher, and lower benefits in the PT+ scenario when congestion is lower.

We can conclude from these scenarios that the public transport service level does not seem to be a very important determinant of the effectiveness of congestion charges. It is 
true that more attractive public transport makes the shift from car to public transport easier, and hence increases the effectiveness of the charges - but the magnitude of this effect seems to be smaller than what is often argued. The theoretical analyses indicate that improved public transport will have two opposite effects on total benefits of the charges: benefits increase because the demand elasticity increases (k decreases, the demand curve becomes flatter), but they decrease because overall demand (and hence congestion) decreases (the demand curve shifts to the left and $m$ become smaller). The opposite is expected if the PT service level becomes lower. The empirical analyses presented here shows that both these effects appear, but that the effect from the change in congestion level dominates, and hence total charging benefits decrease when PT is improved.

\section{The impact of bypasses}

In the scenario without any bypass around the inner city (Bypass-), traffic volumes across the cordon increase and congestion, particularly on the inner city streets, becomes higher. The congestion in the inner city increases since the traffic to/from north to south using the bypass in the first place now is forced to travel through the inner city. Congestion increases less on the arterials because the bypass does in fact not primarily serve as a substitute to the bypass, as it is often is regarded, because drivers are reluctant to switch to the bypass due to severe congestion there. On the contrary, the model results suggest that the bypass works more as a complement to the charged routes. That is, some of the traffic using the congested links to and from the inner city also uses the bypass, and these flows are reduced when the bypass is removed.

The relative traffic reduction of the charges increases slightly and does not reduce, as expected if the bypass serves as a substitute to the charged routes. This is another sign that the bypass does not work primarily as a substitute to the charged route. The share of diverted traffic switching to public transport increases, however; apparently, changing destination becomes more difficult without the bypass, relatively speaking. Adaptation costs remain remarkably unchanged, but total benefits becomes much higher because of the higher congestion levels.

We can conclude that the effectiveness of the charges would surprisingly not reduce had there been no bypass. The adaptation strategy changes - mode change becomes a more important strategy when it becomes more difficult to change destinations - but the general cost elasticity of traffic remains largely unchanged. Just as before, the most important determinant of total benefits is the congestion level.

When a new high-capacity bypass is added east of the inner city (Bypass + ), congestion is reduced substantially, both on arterials and on inner city streets. The new bypass increases the effectiveness of the charges considerably: the traffic reduction increases from $-15 \%$ to $-23 \%$. Apparently, this new bypass works as an alternative for many drivers wanting to avoid the charges. The travel time savings and total benefits of the charges are much smaller, however, since congestion levels have been dramatically reduced. Compared to the other scenarios, adaptation costs are also much higher. This is consistent with the one-market model in section 4, showing that adaptation cost increases because the higher driving cost for the remaining drivers is not compensated by shorter travel times to the same extent as in the other scenarios. The adaptation cost increases also due to the higher demand elasticity because more drivers are priced off the road (this is also consistent with the one-market model when congestion is low).

\section{Increased road capacity}


In the final scenario, capacity on the arterial roads leading to the inner city is increased. This reduces congestion on the arterials, as expected, but on the other hand, congestion in the inner city increases somewhat since the decreased arterial congestion attracts higher traffic volumes across the cordon. Capacity on inner city streets remains unchanged, which is a natural assumption; this capacity is constrained by the dense urban conditions of the city. The relative traffic reduction from the charges' remains largely unchanged, which is expected. Total benefits decrease, since congestion is lower; but since congestion in the inner city is still high, the charges still generate substantial benefits.

\section{CONCLUSIONS}

Obviously, effects and benefits of congestion charges will depend on the characteristics of the specific city where it is introduced. While this statement in its general form is trivially true, the extent of this dependency is not obvious. Specifically, this argument has often been used to discard the general experiences from cities such as Stockholm, London and Milan as specific to these particular cities, and not transferable or applicable to other cities with, e.g., different public transport provision, congestion levels or road network topologies. The purpose of this paper is to shed some light on this issue by investigating to what extent the effects and benefits of the Stockholm congestion charges depend on specific features of the Stockholm transport system.

Our main conclusion is that although the social benefit of a given charging system is considerably and non-linearly dependent on initial congestion levels, the effects on traffic volumes and adaptation costs are surprisingly stable with respect to changes in the transport system. In absolute terms, the effectiveness and benefits change the most in the scenario where a bypass is added, reducing the baseline congestion and increasing the price elasticity. Travel time savings are reduced, while the volume reduction and adaptation cost increases. The latter then exceeds the travel time benefit and the total benefit is even negative (because the size of the charge is then evidently set too high). Even though the effects on travel behavior in general are stable across scenarios, the way they change between scenarios is consistent with the one-market demand-and-supply model.

Specifically, the level of public transport provision has only small effects on baseline congestion, and therefore on the total benefit of the charges. Interestingly, adaptation cost, traffic reduction across the cordon and the share of drivers priced off the road diverting to public transport are also relatively insensitive to the level of public transport provision, contrary to the common argument that public transport provision is crucial for effectiveness and efficiency. Drivers can adapt in many different ways besides switching to public transport, which explains the robustness of our results.

In the case of Stockholm, mode choice is one the most important adaptation strategies, particularly for commuters. The share of travelers priced off the roads that divert to public transport is around 30\%. This is fairly high due to the high initial markets share for public transport. It can be questioned to what extent the conclusions about the effectiveness of charges are transferable to cities where public transport is virtually nonexistent, like some US cities, or to cities where crowding in the public transport system is severe. (In Stockholm, this is less of a problem, since the public transport share is so high that the diverted car drivers make up only a small increase in relative terms.) However, the existence of many other adaptation strategies suggests that our conclusions are fairly robust. 
Stockholm is special in the sense that its network topology is relatively simple. The bottlenecks are situated along a natural cordon around the inner city, with few ratrunning problems. In other cities, system design may be more complicated. Gothenburg is a recent example, where the current design consists of a cordon with additional charging borders sprouting out from the cordon. Sprawling cities with large networks and highly dispersed congestion problems, common in the US, pose other problems in terms of the system design. However, this merely underscores the necessity to adapt the design to the particular structure and congestion problems of the city, as pointed out above. It does not necessarily weaken the main conclusion of this paper, suggesting that the behavioral responses to congestion charges are relatively independent of characteristics such as public transport provision and bypasses than what is often argued.

Congestion charges can also be used as a fiscal policy, to raise revenue. While we find that the charged traffic volume and therefore also the revenues indeed are relatively stable across scenarios, the efficiency of this fiscal policy, in terms of social benefit per collected revenues varies considerably between scenarios.

We conclude by summarizing our results with respect to common arguments against transferability listed in the introduction.

"If we had better public transport we would not need congestion pricing."

Our results suggest that better public transport indeed reduces traffic volumes and congestion to some extent, and vice versa. However, these reductions are rather small despite substantial changes in public transport supply, and hence the benefits of the charges remain considerable even in a scenario with substantial improvements of the public transport system. Generally speaking, it seems difficult to improve public transport so much that congestion charges would not generate substantial benefits.

"Our public transport is less extensive than in Stockholm so charging would not have any effect."

When alternatives to driving are made less attractive, the effect of the charges on road traffic decreases, as expected. However, this change in cost elasticity seems much smaller than might be expected: in our results, the charges' effect on traffic volumes remains almost unchanged despite considerable degradations of the public transport supply.

"If we had more bypasses, congestion pricing would not be needed."

More bypasses have effects in two directions: on the one hand, increasing bypass capacity reduces congestion levels, and hence the benefit of introducing congestion charges. On the other hand, the effectiveness of the charges in terms of traffic reduction increases when a new bypass is introduced in the model, since more alternatives become available for drivers. Of course, there is ample theoretical and empirical evidence that trying to solve urban congestion with bypasses will be inefficient in the long run, but it is apparent from our results that bypass capacity will affect congestion levels (at least in the relatively short run studied here) and adaptation costs.

"We do not have a bypass where priced off drivers can divert so charging would not have any effect."

Although the effectiveness of the charges increases when a second bypass is added, the reverse is not true in our case study: effects of the charges remain almost unchanged even when the only existing bypass is taken away. The difference is that rather than changing route or destinations, more drivers change mode instead. This is partly because the bypass serves as a complement to the charged links rather than a substitute. The 
general conclusion is that it is difficult to understand how different parts of a transport system work as complements or substitutes without a transport model.

"If we had more road capacity on the arterials we would not need congestion pricing."

Increased arterial road capacity does indeed reduce congestion on the arterials, as expected, but on the other hand, inner-city congestion increases since the decreased arterial congestion attracts higher traffic volumes across the cordon. In our results, the relative traffic reduction and benefits remains therefore largely unchanged, even if the latter reduces slightly. In general, this will obviously depend on the network topology; but it is probably a general conclusion that increasing arterial capacity will increase inner-city congestion, and that the capacity of the inner-city street network is even more difficult to expand.

In conclusion, our results suggest that the effects and benefits of the Stockholm charges are less sensitive to specific features of the transport system than might have been expected. This implies that the experiences indeed seem to be transferable, generally speaking, although our results also emphasize that it is important to take local characteristics into account when designing a congestion charging system (choosing charge levels, time differentiation and checkpoint locations). Our results suggest that it is primarily the congestion level that determines the benefits obtained from congestion charges, rather than the specific features of the transport system.

\section{ACKNOWLEDGMENTS}

We are grateful to Mats Tjernqvist and Tobias Thorsson (WSP Analysis \& Strategy) for running the transport model scenarios, and to VINNOVA for financial support.

\section{REFERENCES}

Attard, M., Enoch, M., 2011. Policy transfer and the introduction of road pricing in Valletta, Malta. Transport Policy 18, 544-553. doi:10.1016/j.tranpol.2010.10.004

Bartley, B., 1995. Mobility Impacts, Reactions and Opinions - Traffic demand management options in Europe: The MIRO Project. Traffic Engineering and Control 36, 596.

Börjesson, M., Eliasson, J., Hugosson, M.B., Brundell-Freij, K., 2012. The Stockholm congestion charges -5 years on. Effects, acceptability and lessons learnt. Transport Policy 20, 1-12. doi:10.1016/j.tranpol.2011.11.001

Dolowitz, D.P., Marsh, D., 2000. Learning from Abroad: The Role of Policy Transfer in Contemporary Policy-Making. Governance 13, 5-23. doi:10.1111/09521895.00121

Eliasson, J., 2008. Lessons from the Stockholm congestion charging trial. Transport Policy, Transport Policy 15, 395-404.

Eliasson, J., 2010. So you're considering introducing congestion charging? Here's what you need to know: An FAQ based on Stockholm's experiences (No. 2010-04), International Transport Forum Discussion Papers.

Eliasson, J., Börjesson, M., Brundell Freij, K., Engelson, L., Van Amelsfort, D., 2013. Accuracy of congestion pricing forecasts. Transportation Research A 52, 34-46. doi:10.1016/j.tra.2013.04.004

Eliasson, J., Hultkrantz, L., Nerhagen, L., Rosqvist, L.S., 2009. The Stockholm congestion charging trial 2006: Overview of effects. Transportation Research Part A: Policy and Practice 43, 240-250. doi:10.1016/j.tra.2008.09.007 
Eliasson, J., Jonsson, L., 2011. The unexpected "yes": Explanatory factors behind the positive attitudes to congestion charges in Stockholm. Transport Policy 18, 636647. doi:10.1016/j.tranpol.2011.03.006

Hau, T.D., 1992. Economic Fundamentals of Road Pricing: A Diagrammatic Analysis (No. WPS 1070), Policy Research Working Papers. World Bank.

Jones, P., 2003. Acceptability of Road User Charging: Meeting the Challenge, in: Schade, J. and Schlag, B. (eds.): Acceptability of Transport Pricing Strategies. Elsevier, Oxford.

Leape, J., 2006. The London Congestion Charge. Journal of Economic Perspectives 20, 157-176.

Lindsey, C.R., Verhoef, E.T., 2000. Traffic Congestion and Congestion Pricing (No. 00101/3). Tinbergen Institute Discussion Paper.

Marsden, G., Stead, D., 2011. Policy transfer and learning in the field of transport: A review of concepts and evidence. Transport Policy 18, 492-500. doi:10.1016/j.tranpol.2010.10.007

Richardson, H.W., Bae, C.-H.C., 2008. Road Congestion Pricing in Europe: Implications for the United States. Edward Elgar Publishing.

Santos, G., Shaffer, B., 2004. Preliminary Results of the London Congestion Charging Scheme. Public Works Management Policy 9, 164-181. doi:10.1177/1087724X04268569

Schade, J., Schlag, B., 2003. Acceptability of urban transport pricing strategies. Transportation Research Part F: Traffic Psychology and Behaviour 6, 45-61. doi:10.1016/S1369-8478(02)00046-3

Schlag, B., Schade, J., 2000. Public acceptability of traffic demand management in Europe. Traffic Engineering+ Control 41, 314-18.

Timms, P., 2011. Urban transport policy transfer: "bottom-up" and "top-down" perspectives. Transport Policy 18, 513-521. doi:10.1016/j.tranpol.2010.10.009

Vickrey, W., 1973. Pricing, metering, and efficiently using urban transportation facilities. Highway Research Record 476, 36-48.

Walters, A.A., 1961. The Theory and Measurement of Private and Social Cost of Highway Congestion. Econometrica 29, 676-699. doi:10.2307/1911814 


\section{APPENDIX}

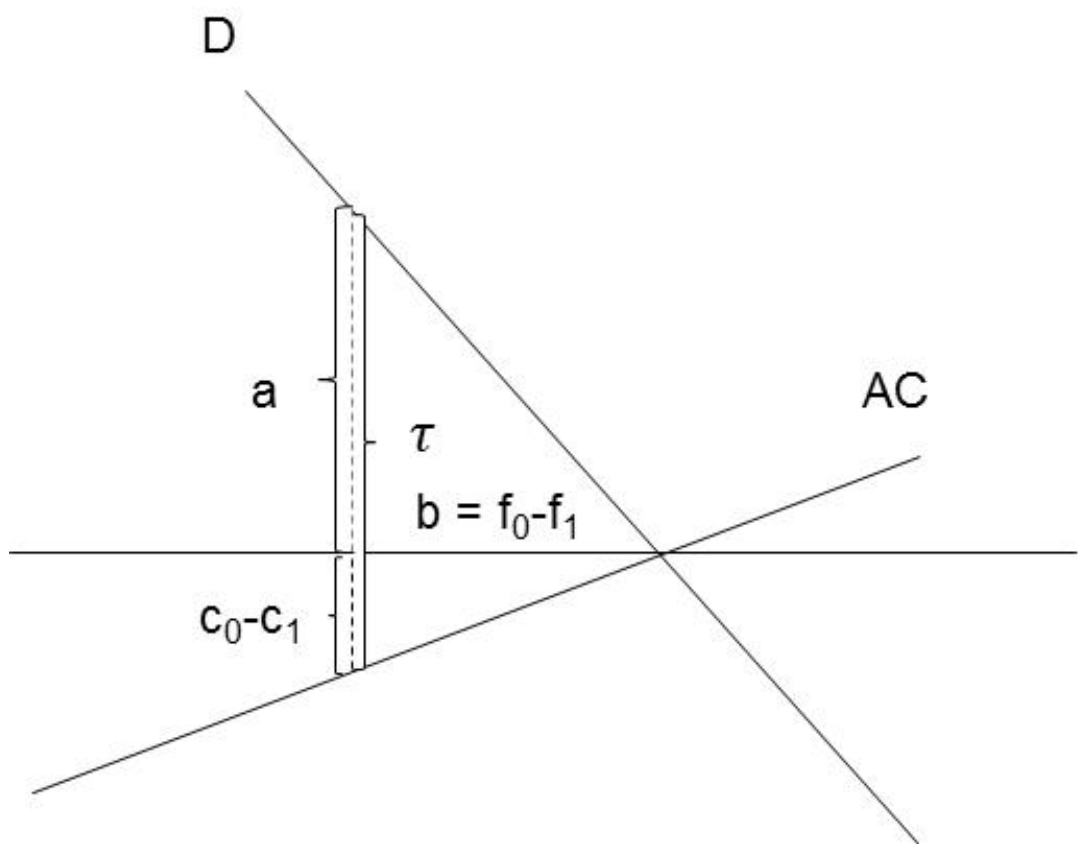

Figure 5: Demand and AC curves.

Assume a linear demand curve D with slope $-k$ and linear AC function with slope $m$, and a constant congestion charge $\tau$. To simplify let $a=\tau-\left(\mathrm{c}_{0}-\mathrm{c}_{1}\right)$ and $b=\mathrm{f}_{0}-\mathrm{f}_{1}$. Then we have:

$$
\begin{gathered}
\frac{a}{b}=k \\
\frac{\tau-a}{b}=m
\end{gathered}
$$

From this we compute:

$$
\begin{aligned}
& a=\frac{\tau k}{k+m} \\
& b=\frac{\tau}{k+m}
\end{aligned}
$$

The adaptation cost is therefore:

$$
\text { adaptation cost }=\frac{a b}{2}=\frac{k \tau^{2}}{2(k+m)^{2}}
$$

The travel time benefit for drivers staying on the road $\left(\mathrm{c}_{0}-\mathrm{c}_{1}\right)$ is:

$$
\text { travel time benefits }=\tau-a=\frac{\tau m}{k+m}
$$

